\title{
Recombinant Human Granulocyte Colony-Stimulating Factor is Associated with Increased Risk of Metastasis in NSCLC Patients Following Postoperative Chemotherapy: A Retrospective Cohort Study
}

\author{
Yong Wang \\ First Affiliated Hospital of Nanchang University \\ Chen Fang \\ First Affiliated Hospital of Nanchang University \\ Shangkun Yuan \\ First Affiliated Hospital of Nanchang University \\ Renfang Chen \\ First Affiliated Hospital of Nanchang University \\ Lin Chen \\ Jiangxi Provincial People's Hospital \\ Xiaotong Qiu \\ First Affiliated Hospital of Nanchang University \\ Xiaoying Qian \\ First Affiliated Hospital of Nanchang University

\section{Xinwei Zhang} \\ First Affiliated Hospital of Nanchang University \\ Zhehao Xiao \\ First Affiliated Hospital of Nanchang University

\section{Qian Wang} \\ First Affiliated Hospital of Nanchang University \\ Biqi Fu \\ First Affiliated Hospital of Nanchang University

\section{Xiaoling Song} \\ First Affiliated Hospital of Nanchang University
}

Yong Li ( $\square$ liyongcsco@email.ncu.edu.cn)

The First Affiliated Hospital of Nanchang University

\section{Research}

Keywords: Recombinant human granulocyte colony-stimulating factor (rhG-CSF), Metastasis, Non-small-cell lung cancer (NSCLC), Distant organ metastasis (DOM)

Posted Date: May 7th, 2021

DOl: https://doi.org/10.21203/rs.3.rs-407638/v1

License: (c) (1) This work is licensed under a Creative Commons Attribution 4.0 International License. Read Full License 


\section{Abstract}

Background: Recombinant human granulocyte colony-stimulating factor (rhG-CSF), which can reduce neutropenia events, is widely used in cancer patients receiving chemotherapy. However, the effects of rhG-CSF on distant organ metastasis (DOM) in non-small cell lung cancer (NSCLC) patients following postoperative chemotherapy remain unclear.

Methods: A retrospective cohort study was performed on NSCLC patients who suffered complete surgical resection and postoperative system chemotherapy at The First Affiliated Hospital of Nanchang University between 1 January 2012 and 31 December 2017. The effect of rhG-CSF on DOM was assessed, regulating with other confounding factors using Cox regression analyses.

Results: We identified 307 NSCLC patients who received postoperative system chemotherapy ( $n=246$ rhG-CSF group, $n=61$ No rhG-CSF group). The incidence of DOM in postoperative NSCLC patients with rhG-CSF treatment was observably higher than without rhG-CSF $(48.3 \%$ vs. $27.9 \%, p<0.05)$. Univariate regression analysis revealed that rhG-CSF and clinical stage were the independent risk factor of Metastasis-free survival (MFS) ( $p<0.05$ ). rhG-CSF users had a higher risk of DOM (adjusted HR: 2.33, 95\% Cl: 1.31-4.15) than nonusers of rhG-CSF. The association between rhG-CSF and risk of DOM was significant only among patients presenting with myelosuppression (HR: 3.34, 95\% Cl: 1.86-6.02), not among those without myelosuppression (HR: 0.71, 95\% Cl: 0.17-2.94, Interaction $p$-value $<0.01)$. The risk increased with higher dosage density of rhG-CSF use, comparing those using rhG-CSF versus no users ( $p$ for trend<0.001).

Conclusion These analyses indicated that rhG-CSF use is related to DOM following postoperative chemotherapy in NSCLC.

\section{Background}

Non-small cell lung cancer (NSCLC) is one of the most common cancers and the leading cause of cancer death worldwide ${ }^{[1]}$. Surgery and postoperative adjuvant chemotherapy are still the main and stand treatments for early-stage NSCLC. However, the emergence of distant organ metastasis (DOM) is the primary reason for cancer treatment failure and tumor-associated death. It is the critical risk factor affecting patients' survival prognosis even undergoing curative surgical resection ${ }^{[2]}$. The DOM rate of NSCLC still positively arrives at $50 \%[3]$, brain, liver, adrenal gland, and bone are generally the distant organs where NSCLC is more likely to metastasize preferentially. Over half of the NSCLC patients have metastases at diagnosis ${ }^{[4]}$, and metastasis of tumors was the primary reason for death in cancer patients ${ }^{[5]}$. Hence, appreciation of the risk factors for distant metastasis may facilitate selecting the scientific and reasonable strategies for reducing the risk of metastasis, improving the curative rate and the life quality of NSCLC.

Recombinant human granulocyte colony-stimulating factor (rhG-CSF), commonly used for cancer patients following myelosuppressive cytotoxic chemotherapy, is to decrease the risk of potentially fatal infections and hospitalization associated with febrile neutropenia $(\mathrm{FN})$ and then ensure the dose intensity of chemotherapy that improves the overall survival $(\mathrm{OS})^{[6]}$. However, as a cytokine, granulocyte colony-stimulating factor (G-CSF) is reported to be equipped with pro-tumor activities in numerous studies recently ${ }^{[7]}$. Consequently, increasing proof revealed that the use of exogenous G-CSF could promote cancer metastasis in preclinical cancer models ${ }^{[8,9]}$. Kumar et al. ${ }^{[10]}$ found that G-CSF contributed to increased migration and survival of ovarian cancer via targeting the downstream JAK2/STAT3 signaling pathway. Moreover, in the head and neck squamous cell carcinoma (HNSCC) mice model ${ }^{[11]}$, G-CSF was associated with invasive and malignant tumor growth.

Nevertheless, both effects above would be eliminated as the existence of G-CSF inhibitors. However, rarely clinical data indicate that rhGCSF use in cancer patients is related to a high DOM risk. Besides, the impact of rhG-CSF treatment among postoperative chemotherapy patients with myelosuppression or not on metastasis of cancer, especially in NSCLC, remains unclear. Therefore, we examined the prometastasis character of rhG-CSF in a retrospective cohort of NSCLC patients who received chemotherapy after operation. It was wishful that these data would provide experimental evidence to lessen cancer metastasis's occurrence pursuing the G-CSF.

\section{Methods}

\section{Study design and population}

This retrospective cohort study was approved by the Ethics Committee of the First Affiliated Hospital of Nanchang University, China, and abide by the rules of the Declaration of Helsinki. We reviewed the digital medical records of all patients, a total of 307 consecutive

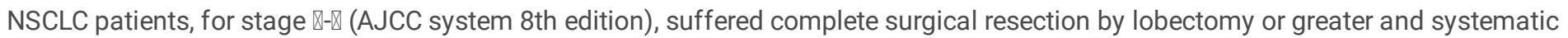
lymph node dissection and received postoperative system chemotherapy at The First Affiliated Hospital of Nanchang University between 
1 January 2012 and 31 December 2017. Complete resection was defined as the macroscopic and microscopic absence of residual cancer (R0). Patients were excluded if they had been diagnosed with cancer other than NSCLC before the surgery, or if they underwent limited resection (segmentectomy or wedge resection), incomplete resection, neoadjuvant chemotherapy/radiotherapy, or metastasis occurred before surgery or before receiving the first postoperative chemotherapy, or follow-up time of fewer than 30 days after surgery. All patient records were anonymized before analyses. Follow-up duration was counted from the day of surgery to the day of DOM diagnosis, last follow-up, or lost to follow-up. The last follow-up time was 31 December 2020.

Clinical records data of the potential cases were collected by one research group blinded to the outcome status, and outcome and follow-up of the case were collected by another research group blinded to the exposure status. Then, the first and the corresponding author were responsible for all data analysis and interpretation.

\section{Treatment and data collection}

Systemic chemotherapy was administered after the surgery in the first-line treatment of NSCLC. During postoperative treatment, chemotherapy can quickly induce myelosuppression, and rhG-CSFs were given to relieve or prevent myelosuppression. Patients were divided into two groups, ever or never rhG-CSF users. Ever rhG-CSF users were those who had at least one rhG-CSF prescription. The effects of the dosage of rhG-CSF exposure on postoperative metastasis risk of NSCLC were also analyzed. Four subgroups $(\leq 500 \mu \mathrm{g}$, $500-1000 \mu \mathrm{g}, 1000-1500 \mu \mathrm{g},>1500 \mu \mathrm{g}$ ) were divided into based on the cumulative total rhG-CSF dosage. Given the impact of dosage used over time, dosage density of rhG-CSF, on the metastasis, to evaluate the effects of density of rhG-CSF treatment on the outcome variable metastasis, length of rhG-CSF exposure time (in days) was measured since the first prescription to the last to calculate the dosage density of rhG-CSF treatment.

We reviewed medical records to extract data on demographics, clinicopathological characteristics, and treatment histories: age, weight, sex, smoking habit (never smoked or have smoked), anamnesis, histologic type, grade, clinical stage. Simultaneously, during the postoperative chemotherapy and follow-up period, regimen and number of chemotherapy, the severity of myelosuppression (Common Terminology Criteria for Adverse Events (CTCAE), version 4.03$)$, fever $\left(>37.5^{\circ} \mathrm{C}\right.$, by axillary mercury thermometers), antibiotics were collected.

\section{Study assessments}

All selected NSCLC patients achieved disease-free status after surgery. We reviewed clinic notes and checked the whole routine imaging records of enrolled patients, including ultrasound (US), thoracic radiography, computed tomography (CT), magnetic resonance imaging (MRI), and emission computed tomography (ECT) at the time of diagnosis or during follow-ups, to assess their metastatic status.

Metastasis-free survival (MFS) was defined as the duration from the day of chest surgery to investigator-assessed radiographic organ or node metastasis. MFS was otherwise censored on the last follow-up date if patients were alive and without any evidence of metastasis. Simultaneously, patients' status of metastasis at one year, two years, and three years after surgery were also measured. Patients without documented clinical or radiographic disease date of metastasis were censored at the last follow-up.

\section{Statistical analyses}

Continuous variables are shown as means \pm SDs, and categorical variables are shown as frequencies (percentages). The t-test (normal distribution) or Kruskal-Wallis rank-sum test (abnormal distribution) for continuous variables and $\chi^{2}$ tests for categorical data were used to analyze each covariate's required data distribution between the rhG-CSF and No rhG-CSF groups. We took advantage of the KaplanMeier method to calculate overall MFS rates, and the differences in survival for univariate comparisons were calculated using the logrank test. Forest plots were employed to describe the underlying effect modification by each covariate. Interaction analysis was conducted by calculating the respective categorical variable product terms individually in the model. Further, whether rhG-CSF and other covariates had an independent effect on NSCLC patients' metastasis following postoperative chemotherapy separately was evaluated through univariate logistic regression and multivariate logistic regression models. The level of significance was established at $p=0.05$. The statistical software packages R ( http://www.R-project.org, The R Foundation) and EmpowerStats (http://www.empowerststs.com, $\mathrm{X} \& Y$ Solutions, Inc., Boston, MA) were used to conduct all of the statistical analyses.

\section{Result}

\section{Patients' baseline characteristics}


Among the 307 postoperative NSCLC patients included in the study, 246 (80.1\%) patients who received rhG-CSF treatment during chemotherapy were regarded as the study group (rhG-CSF group), and 61 (19.9\%) patients who untreated with rhG-CSF were included in the control group (No rhG-CSF group). The clinical characteristics and baseline parameters of the No rhG-CSF and rhG-CSF group are presented in Table 1. The mean age (56.52 years vs. 57.74 years) of participants were mainly similar in the No rhG-CSF group and rhGCSF group. Approximately half the number of patients treated with the Taxane+Platinum chemotherapy regimen (45.90\% vs. $41.06 \%)$ and received four cycles of chemotherapy (47.54\% vs. $55.69 \%)$ after surgery in both groups. Patients with myelosuppression were observed more frequently in the rhG-CSF group than those without rhG-CSF treatment ( $56.50 \%$ vs. $8.20 \%, p<0.001)$. Since in the clinical practice, most patients with myelosuppression after chemotherapy tend to use rhG-CSF. Essential characteristics were comparable between the No rhG-CSF and rhG-CSF group. Patients in the two groups were similar in terms of age, weight, gender, smoking, histology, differentiation, clinical-stage, chemotherapy, fever, antibiotic, complications. As we excluded patients with the poor general physical condition before surgery and chemotherapy treatment, the Eastern Cooperative Oncology Group performance status (ECOG PS) level of all postoperative NSCLC patients was $0-1$. Therefore, there was no noticeable difference between the rhG-CSF and No rhG-CSF group.

\section{Prognostic factors for metastasis}

In the overall study, 307 postoperative NSCLC patients, a total of $136(44.30 \%)$ distant organ metastasis, occurred following the chest operation over the median follow-up period of 33.63 months. Among that, $119(48.3 \%)$ patients in the rhG-CSF group and 17 (27.9\%) patients in the No rhG-CSF group, suggesting that the DOM rate was significantly higher in the study group compared within the control group $(p<0.05)$. rhG-CSF treatment was significantly correlated with metastasis by univariate Cox regression analysis $(\mathrm{HR} 2.30,95 \% \mathrm{Cl}$ $1.36-3.88, p<0.01)$. Sincerely, we found the different dosage and density gradients of rhG-CSF likely play an essential role in distant organ metastases (Table 2). Besides, clinical-stage were also associated with metastasis following NSCLC postoperative chemotherapy

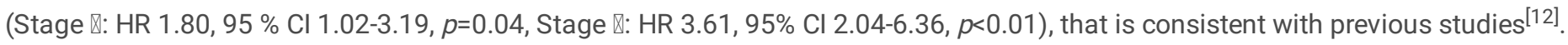

\section{Impact of rhG-CSF treatment on the risk of metastasis}

The Kaplan-Meier curve of the metastasis-free survival rates of postoperative NSCLC patients is shown in Figure 1. The risk of DOM was substantially increased in the rhG-CSF group compared with the No rhG-CSF group. Furthermore, rhG-CSF treatment was also associated with poorer MFS among postoperative follow-up one year (HR 4.00, 95\% Cl 1.45-11.05, $p=0.007$ ), two years ( $\mathrm{HR} 3.11,95 \% \mathrm{Cl} 1.50-6.43$, $p=0.002$ ) and three years (HR 2.59, 95\% Cl 1.42-4.71, $p=0.02$ ) (Fig. 2).

Accounting for other vital covariates, Table 3 further quantifies the efficacy of rhG-CSF in promoting metastasis by multivariate Cox regression analysis adjusted for part or all the confounders. For those with rhG-CSF treatment, compared with the No rhG-CSF group, the DOM incidence was increased from $27.8 \%$ to $48.3 \%$ in postoperative NSCLC patients, representing a relative risk increase of 1.41 times in the adjusted I model (HR 2.41, 95\% Cl 1.42-4.11, p<0.01) and 1.33 times in the adjusted II model (HR 2.33, 95\% Cl 1.31-4.15, $p<0.01)$. We performed similar analyses for postoperative follow-up one year, two years, and three years, rhG-CSF treatment was associated with an increased risk of metastasis in the postoperative NSCLC patients (Table 4). rhG-CSF was be recognized as an independent adverse factor of DOM.

\section{Subgroup analyses by important covariables}

To further confirm the results that rhG-CSF was an independent adverse factor of metastasis are robust to potential confounders, we performed subgroup analyses by major covariables that possible related to metastasis, including age, sex, weight, smoking, histology, differentiation, complications, clinical-stage, chemotherapy regime, number of chemotherapy, myelosuppression, fever, antibiotic. Subgroup analysis showed a similarly consistent pattern (Fig. 3), there were no significant interactions in most of the covariables (interaction $p$-value $>0.05$ ) except for myelosuppression (interaction $p$-value $<0.01$ ). Among patients presented without myelosuppression after chemotherapy, rhG-CSF treatment resulted in a significantly high risk of metastasis (HR 3.34, 95\% Cl 1.86-6.02, $p<0.01$ ). In contrast, rhG-CSF treatment reduced the risk of metastasis in patients who presented myelosuppression (HR 0.71, $95 \% \mathrm{Cl} 0.17-2.94, p>0.05$ ). Compared with the patients who with myelosuppression after chemotherapy, patients who presented without myelosuppression had a higher risk correlated of rhG-CSF use with metastasis (HR 3.34 vs. 0.71 , interaction $p$-value $<0.01$ ), as well as in postoperative follow-up one year (HR 6.67 vs. 1.05, interaction $p$-value $<0.01$ ), two years (HR 5.26 vs. 0.70 , interaction $p$-value $<0.01$ ) and three years (HR 4.11 vs. 0.71 , interaction $p$-value $<0.01$ ) (Fig. 4).

\section{Effects of dosage and density of rhG-CSF treatment on the risk of metastasis}


We further examined the degree to which rhG-CSF can increase the risk of metastasis in various dosage gradient ranging. We observed an increased risk of metastasis with rhG-CSF use in different dosages, except for the 1000 $\mu$ g- $1500 \mu \mathrm{g}$ gradient group $(p>0.05)$, in both the non-adjusted and adjusted models (Table 3). However, the risk of metastasis did not increase as the dosage of rhG-CSF increased ( $p$ for trend>0.05). When the factor of time was taken into account, dosage density of rhG-CSF, the dosage of rhG-CSF used in the length of rhG-CSF exposure time, positive relations between dosage density of rhG-CSF treatment and risk of metastasis were observed for all models. Statistically significant results of trend tests were obtained in the total sample ( $p$ for trend<0.001) (Table 3 ). Subsequently, the analogous consequences were exhibited in the postoperative follow-up one year, two years, and three years ( $p$ for trend $<0.05)(T a b l e 4)$.

\section{Discussion}

Distant organ metastasis is always associated with poor prognosis and shorter survival in NSCLC patients ${ }^{[13]}$. It is not entirely clear that the specific adverse factors for DOM in NSCLC patients with postoperative chemotherapy. To the best of our knowledge, the current study is the first-size retrospective cohort study to understand the effect of rhG-CSF on cancer metastasis in NSCLC patients with postoperative chemotherapy. The median time to postoperative metastasis of NSCLC patients was 37.23 months in our study, which was in line with that of NSCLC patients in China ${ }^{[14]}$. Meanwhile, consistent with routine clinical medication ${ }^{[15]}$, our research discovered that rhG-CSF is commonly more used in NSCLC patients with multiple chemotherapy treatments and myelosuppression. Hence, the trend that we observed in the research is justifiable.

The influence of tumor staging on patients' metastasis has been generally admitted ${ }^{[16]}$. In terms of pathophysiology, a sizeable solid part size of lung cancer could generate large metastatic lymph nodes to enhance metastasis risk ${ }^{[17,18]}$. Moreover, high G-CSF levels within tumor tissue might represent a high risk of DOM and a worse prognosis ${ }^{[19,20]}$. As our present study found, those two adverse factors above were also related to DOM occurrence. Poor nutrition conditions have been regarded as a powerful underlying prognosticator of postoperative $D_{O M}{ }^{[16,21]}$. To avoid the confounding factors impacting the results as much as possible, we removed patients with PS scores $\geq 2$ before postoperative chemotherapy in the analysis. Besides, the total dosage of rhG-CSF used was influenced by the number of chemotherapy, chemotherapy regimens, and the degree of myelosuppression. Hence, chemotherapy cycle, regimens, and myelosuppression staus were also adjusted in the analysis. After taking those potential factors into adjustment, results suggest that rhG-CSF has an intimate connection with DOM following postoperative chemotherapy. As the loss to patients' follow-up might result in withdrawal bias, it also likely has distorted the results due to the proportion of patients who lost to follow-up will relatively increase with the follow-up time extension. We also analyzed the correlation between rhG-CSF treatment and DOM based on postoperative follow-up one year, two years, and three years. The outcomes showed that the risk of DOM was significantly higher than that in the No rhG-CSF group at one, two, or three years of follow-up after surgery. It came to the same conclusion that rhG-CSF connected with DOM in this condition, which offered persuasive evidence for our study.

CSF has first discovered by Don Metcalf et $a^{[22]}$, subsequently, it was founded that mice treated with rhG-CSF leaded a high level of granulocytes in the spleen ${ }^{[23]}$, then leading to the widely use of rhG-CSF in clinical practice to prevent the development of FN in patients undergoing intensive chemotherapy that induced myelosuppression. Patients with myelosuppression following chemotherapy are featured by neutropenia, efficiently inducing FN or even lethal infection. As is well-known, rhG-CSF treatment supplementation plays a vital role in allowing patients to safely accomplished a myelosuppression-toxic chemotherapy regimen, improving disease-free survival (DFS) and OS of patients after chemotherapy ${ }^{[24]}$. Notably, the use of rhG-CSF in clinical has increased over the 30 years ${ }^{[24]}$. From our study, $80.13 \%$ of patients had been injected with rhG-CSF at a mean dose of $885.89 \mu \mathrm{g}$. Regrettably, our study revealed that rhG-CSF injection during postoperative chemotherapy is related to the occurrence of DOM. Even more prominently, data further suggested that the risk of DOM elevated with the increase of rhG-CSF dosage density. This also implied that a more precise standard is demanded to direct the use of rhG-CSF to reduce the risk of DOM.

At present, the guidelines for rhG-CSF of National Comprehensive Cancer Network (NCCN) treatment recommend prophylaxis with rhGCSF when the risk of $\mathrm{FN}$ is approximately $20 \%$ or higher, or the risk of $\mathrm{FN}$ ranges $10-20 \%$ combined with one or more risk factors like the aged, recent history of surgery and the like ${ }^{[25]}$. The purpose of prophylaxis with rhG-CSF is to prevent or remit the degree of neutropenia after chemotherapy or shorten the time of neutropenia, so that lower the risk of FN, severe infection, and death. As guidelines introduced $^{[25]}$, compared with prophylactic use of rhG-CSF, no clear enough evidence suggests that the therapeutic use of rhG-CSF could bring outstanding therapeutic value for patients who have had severe infection or neutropenia without fever. In the real world, how many patients will have infections due to neutropenia after chemotherapy as they do not use rhG-CSF treatment? Even if a certain degree of neutropenia happened, it might not be many patients have the occurrence of the events that guidelines focused on. The prospective, 
Phase III, the randomized, double-blind, multicenter study indicates that the FN rate was $5.6 \%$ in the placebo $(n=125)$ group during cycle 1 of chemotherapy in NSCLC patients ${ }^{[26]}$. Zhou et al. ${ }^{[27]}$ found that only $8 \%(n=51)$ of patients with NSCLC who received chemotherapy without rhG-CSF treatment presented FN. There was a relatively low occurrence of FN in NSCLC patients even without rhG-CSF. It was evident that a large proportion of patients borne mild chemotherapy could also get through the risk period after chemotherapy safely in the absence of rhG-CSF. As we can see, guidelines pay close attention to whether the use of rhG-CSF reduces the occurrence of FN and its complications, the risk of infection and death, duration of severe neutropenia, duration of antibiotic use, length of hospital stay, bone pain, and other indicators. However, it may ignore the dark side of rhG-CSF supplements, like promoting cancer metastasis. The risk of metastasis with excessive use of rhG-CSF would increase remarkably in most of those patients, which got us thinking though whether certain precautions, such as avoiding some infection factors and increasing nutrition after chemotherapy, might take the place of rhGCSF usage to lower the risk. Though patients with breast cancer obtained benefits from rhG-CSF use in extending DFS and OS, well, maybe for that any damage from rhG-CSF usage could be whitewashed by the profit supported by dose-intensity chemotherapy regimens ${ }^{[28]}$. Nevertheless, chemotherapy regimens of NSCLC in guidelines most are moderate-risk strategy, unlike high FN risk induced by chemotherapy of breast cancer ${ }^{[25]}$.

Currently, a developing number of studies ${ }^{[29-31]}$ have identified that rhG-CSF can promote primary tumor growth and metastasis in preclinical experiments. In the Lewis lung carcinomas mice model, rhG-CSF combined with paclitaxel (PTX) has been identified to stimulate angiogenesis and succedent tumor regrowth, leading to minimizing the effect of chemotherapy ${ }^{[8]}$. Few positive results are revealed in clinical studies. The reason lies in rhG-CSF was injected before or very soon after building tumor animal models ${ }^{[7]}$. It gives full play to the rhG-CSF character in promoting metastasis. However, in clinical treatment, diagnosed patients received rhG-CSF after chemotherapy. Maybe the pro-metastasis effect of rhG-CSF is exerted in a limited time, or the benefits chemotherapy brought would veil the disadvantage of rhG-CSF. Similarly, our research determined that the function of rhG-CSF in promoting metastasis rely on dosage density rather than the total dosage. Therefore, using rhG-CSF frequently in a short time puts patients at high risk of metastasis and worse prognosis. It also arouses us to think deeply that whether we should avoid high-frequency rhG-CSF used in a short time during clinical practice. Though the benefits rhG-CSF brings are apparent, accompanied by the risk of DOM increased.

Neutrophil extracellular traps (NETs), the network structure consisting of modified chromatin structures and decorated with given cytoplasmic and granular proteins, probably also play a crucial part in the enhanced risk of DOM with rhG-CSF use ${ }^{[32]}$. NETs, first founded by Brinkmann et al. in $2004^{[33]}$, were released when neutrophils trap and kill pathogenic microorganisms and activate platelets ${ }^{[34]}$. Interestingly, in colorectal cancer (CRC) patients, Tohme et al. discovered, serum NETs levels of patients undergoing hepatectomy markedly elevated, distinguish from that of healthy controls, and greater risk of poor prognosis ${ }^{[35]}$. Besides, abundant studies have hinted G-CSF in aggravating NETs formation in preclinical tumor experiments ${ }^{[32,36,37]}$. Unexpectedly, differ from patients with myelosuppression, rhG-CSF was significantly associated with DOM in NSCLC patients without myelosuppression in the result of our analyses. We would hazard a guess that rhG-CSF injection mainly elevates the level of NETs under the non-myelosuppression circumstances and then encourages DOM in mechanism and validate it in the future. As one of the most common manifestations of infection, fever might be associated with the appearance of NETs. As we speculate, the risk of DOM could be boosted following fever and reduced by the antibiotic treatment. Nevertheless, regrettably, our results do not reflect the hypothesis we proposed, maybe due to the small sample size. Thereby, more samples to validate the proposed hypothesis still needed to gather for analysis in the future.

The analyses of this research offer proof of the effect of rhG-CSF on the development of DOM in NSCLC patients with postoperative chemotherapy. Hence, a physician in clinical practice should give the use of rhG-CSF to NSCLC patients based on chemotherapy regimens and patients' own risk factors using rhG-CSF once myelosuppression exists. Moreover, the recommended guidelines of rhGCSF use should formulate more comprehensive standards. Those populations who are suitable to use rhG-CSF are also worthy of further exploration.

Our study still has the limitations as follows: first of all, for the reason of lost follow-up, we did not dissect the OS of participants in this study which is wanted to be shown in subsequent research. Second, our study subjects only the NSCLC patients who ever received chemotherapy after postoperation. In future studies, more tumor species should also be considered. Besides, DOM was mainly judged through imaging examination and not demonstrated by biopsy, which probably causes false-positive results, despite the diagnosis estimated by two radiologists. Pathological discoveries could be used to supply testimony in terms of microenvironment variations in the metastatic organs. Last, as this was a retrospective study, some selection biases may be present, and prospective research also needed to verify the above conclusion. 


\section{Conclusion}

Among NSCLS patients following postoperative chemotherapy, we found that rhG-CSF use is related to a high risk of metastasis, and this risk may elevate significantly along with the increase of dosage density of rhG-CSF. Also, the study suggests that patients without myelosuppression might get more disadvantages from rhG-CSF. Our findings, if affirmed, lead far-reaching clinical and public health influence, given the highest mortality rate of NSCLC globally. It implies that identifying those patients with or without myelosuppression after chemotherapy could help guide the rational drug use of rhG-CSF and avoid its dark side in clinical usage.

\section{Abbreviations}

G-CSF: granulocyte colony-stimulating factor, rhG-CSF: recombinant human granulocyte colony-stimulating factor, NSCLC: non-small cell lung cancer, DOM: distant organ metastasis, FN: febrile neutropenia, OS: overall survival, HNSCC: head and neck squamous cell carcinoma, CTCAE: Common Terminology Criteria for Adverse Events, US: ultrasound, CT: computed tomography, MRI: magnetic resonance imaging, ECT: emission computed tomography, MFS: metastasis-free survival, ECOG PS: Eastern Cooperative Oncology Group performance status, MFS: metastasis-free survival, DFS: disease-free survival, NCCN: National Comprehensive Cancer Network, PTX: paclitaxel, NETs: neutrophil extracellular traps, CRC: colorectal cancer.

\section{Declarations}

\section{Ethics Approval}

This retrospective cohort study was approved by the Ethics Committee of the First Affiliated Hospital of Nanchang University, China, and abide by the rules of the Declaration of Helsinki.

\section{Consent for Publication}

We gained consent to publish from the participants to report individual patient data.

Availability of data and material

This manuscript included all data collected or analyzed during this research.

\section{Competing interests}

The authors declare no potential conflicts of interest.

\section{Funding}

This study was funded by the National Natural Science Foundation of China (No.81560379, 81460292, 81660315), Surface project of the Natural Science Foundation of Jiangxi Province (No.20181BAB205046, No.20202BAB216031), Technology Supporting Program of Jiangxi Province (No.2015BBG70236), The Key Project of Education Department of Jiangxi Province (No.GJJ170012), Guiding Science and Technology Project of Ganzhou (No. GZ2018ZSF306).

\section{Authors' contributions}

YL designed the research. YW made a significant contribution to the data analyses, and CF drew up the manuscript. SY, RC, and $X Q$, as the first research group, reviewed clinic notes. $X Q, X Z, Z X$, and QW, as the other research group, collected the outcome and follow-up of the case. $\mathrm{LC}$ and BF processed the figures and tables. YL undertook support for the project. All authors have browsed and agreed with the final manuscript.

\section{Acknowledgements}

This study was funded by the National Natural Science Foundation of China (No.81560379, 81460292, 81660315), Surface project of the Natural Science Foundation of Jiangxi Province (No.20181BAB205046, No.20202BAB216031), Technology Supporting Program of Jiangxi Province (No.2015BBG70236), The Key Project of Education Department of Jiangxi Province (No.GJJ170012), Guiding Science and Technology Project of Ganzhou (No. GZ2018ZSF306). 


\section{References}

1. Siegel RL, Miller KD, Jemal A. Cancer statistics, 2019. CA Cancer J Clin. 2019;69(1):7-34.

2. Ekeke CN, Mitchell C, Schuchert M, Dhupar R, Luketich JD, Okusanya OT. Early Distant Recurrence in Patients With Resected Stage I Lung Cancer: A Case Series of "Blast Metastasis". Clin Lung Cancer. 2021;22(1):e132-5.

3. Chen Y, Cai C, Li Y. The impact of baseline brain metastases on clinical benefits and progression patterns after first-line crizotinib in anaplastic lymphoma kinase-rearranged non-small cell lung cancer. Med (Baltim). 2021;100(8):e24784.

4. Chen VW, Ruiz BA, Hsieh MC, Wu XC, Ries LA, Lewis DR. Analysis of stage and clinical/prognostic factors for lung cancer from SEER registries: AJCC staging and collaborative stage data collection system. Cancer. 2014;120:3781-92.

5. Qiu Z, Ye B, Zhao S, Li X, Li L, Mo X, et al. Non-canonical Raf-1/p70S6K signalling in non-small-cell lung cancer. J Cell Mol Med. 2019;23(11):7632-40.

6. Lyman GH, Reiner M, Morrow PK, Crawford J. The effect of filgrastim or pegfilgrastim on survival outcomes of patients with cancer receiving myelosuppressive chemotherapy. Ann Oncol. 2015;26(7):1452-8.

7. Yeo B, Redfern AD, Mouchemore KA, Hamilton JA, Anderson RL. The dark side of granulocyte-colony stimulating factor: a supportive therapy with potential to promote tumour progression. Clin Exp Metastasis. 2018;35(4):255-67.

8. Kowanetz M, Wu X, Lee J, Tan M, Hagenbeek T, Qu X, et al. Granulocyte-colony stimulating factor promotes lung metastasis through mobilization of Ly6G + Ly6C + granulocytes. Proc Natl Acad Sci U S A. 2010;107(50):21248-55.

9. Swierczak A, Cook AD, Lenzo JC, Restall CM, Doherty JP, Anderson RL, et al. The promotion of breast cancer metastasis caused by inhibition of CSF-1R/CSF-1 signaling is blocked by targeting the G-CSF receptor. Cancer Immunol Res. 2014;2(8):765-76.

10. Kumar J, Fraser FW, Riley C, Ahmed N, McCulloch DR, Ward AC. Granulocyte colony-stimulating factor receptor signalling via Janus kinase 2/signal transducer and activator of transcription 3 in ovarian cancer. $\mathrm{Br} J$ Cancer. 2014;110(1):133-45.

11. Gutschalk CM, Herold-Mende CC, Fusenig NE, Mueller MM. Granulocyte colony-stimulating factor and granulocyte-macrophage colony-stimulating factor promote malignant growth of cells from head and neck squamous cell carcinomas in vivo. Cancer Res. 2006;66(16):8026-36.

12. Chao D, Hu G, Li Q. Clinicopathological significance and prognostic value of E-cadherin expression in non-small cell lung cancer: $A$ protocol for systematic review and meta-analysis. Med (Baltim). 2021;100(7):e24748.

13. Black RC, Khurshid H. NSCLC: An Update of Driver Mutations, Their Role in Pathogenesis and Clinical Significance. R I Med J. (2013) 2015;98(10): 25-28.

14. Zhu Z, Chai Y. First-Line. EGFR-TKIs Treatment in Stage I Non-Small-Cell Lung Cancer Patients Harboring EGFR Gene Mutations with Postoperative Intrapulmonary Recurrence. Cancer Manag Res. 2021;13:1667-72.

15. Fujita A, Ohkubo T, Hoshino H, Takabatake H, Tagaki S, Sekine K, et al. Phase II study of cisplatin, ifosfamide, and irinotecan with rhG-CSF support in patients with stage Illb and IV non-small-cell lung cancer. Br J Cancer. 2003;89(6):1008-12.

16. Lin M, Chen QY, Zheng CH, Li P, Xie JW, Wang JB, et al. Effect of Preoperative Tumour Under-Staging on the Long-Term Survival of Patients Undergoing Radical Gastrectomy for Gastric Cancer. Cancer Res Treat. 2021.

17. Zhang F, Zheng W, Ying L, Wu J, Wu S, Ma S, et al. A Nomogram to Predict Brain Metastases of Resected Non-Small Cell Lung Cancer Patients. Ann Surg Oncol. 2016;23(9):3033-9.

18. Cho JY, Leem CS, Kim Y, Kim ES, Lee SH, Lee YJ, et al. Solid part size is an important predictor of nodal metastasis in lung cancer with a subsolid tumor. BMC Pulm Med. 2018;18(1):151.

19. Hollmén M, Karaman S, Schwager S, Lisibach A, Christiansen AJ, Maksimow M, et al. G-CSF regulates macrophage phenotype and associates with poor overall survival in human triple-negative breast cancer. Oncoimmunology. 2016;5(3):e1115177.

20. Welte T, Kim IS, Tian L, Gao X, Wang H, Li J, et al. Oncogenic mTOR signalling recruits myeloid-derived suppressor cells to promote tumour initiation. Nat Cell Biol. 2016;18(6):632-44.

21. Takada K, Shimokawa M, Akamine T, Ono Y, Haro A, Osoegawa A, et al. Association of Low Body Mass Index With Poor Clinical Outcomes After Resection of Non-small Cell Lung Cancer. Anticancer Res. 2019;39(4):1987-96.

22. Burgess AW, Metcalf D. The nature and action of granulocyte-macrophage colony stimulating factors. Blood. 1980;56(6):947-58.

23. Fujisawa M, Kobayashi Y, Okabe T, Takaku F, Komatsu Y, Itoh S. Recombinant human granulocyte colony-stimulating factor induces granulocytosis in vivo. Jpn J Cancer Res. 1986;77(9):866-9. 
24. Lyman GH, Reiner M, Morrow PK, Crawford J. The effect of filgrastim or pegfilgrastim on survival outcomes of patients with cancer receiving myelosuppressive chemotherapy. Ann Oncol. 2015;26(7):1452-8.

25. Crawford J, Becker PS, Armitage JO, Blayney DW, Chavez J, Curtin P, et al. Myeloid Growth Factors, Version 2.2017, NCCN Clinical Practice Guidelines in Oncology. J Natl Compr Canc Netw. 2017;15(12):1520-41.

26. Volovat C, Bondarenko IM, Gladkov OA, Elsässer R, Buchner A, Bias P, et al. Phase III, randomized, double-blind, placebo-controlled, multicenter study of lipegfilgrastim in patients with non-small cell lung cancer receiving myelosuppressive therapy. Springerplus. 2015;4:316.

27. Zhou C, Huang Y, Wang D, An C, Zhou F, Li Y, et al. A Randomized Multicenter Phase III Study of Single Administration of Mecapegfilgrastim (HHPG-19K), a Pegfilgrastim Biosimilar, for Prophylaxis of Chemotherapy-Induced Neutropenia in Patients With Advanced Non-Small-Cell Lung Cancer (NSCLC). Clin Lung Cancer. 2016;17(2):119-27.

28. Han Y, Yu Z, Wen S, Zhang B, Cao X, Wang X. Prognostic value of chemotherapy-induced neutropenia in early-stage breast cancer. Breast Cancer Res Treat. 2012;131(2):483-90.

29. Hamilton JA, Cook AD, Tak PP. Anti-colony-stimulating factor therapies for inflammatory and autoimmune diseases. Nat Rev Drug Discov. 2016;16(1):53-70.

30. Morris KT, Khan H, Ahmad A, Weston LL, Nofchissey RA, Pinchuk IV, et al. G-CSF and G-CSFR are highly expressed in human gastric and colon cancers and promote carcinoma cell proliferation and migration. $\mathrm{Br} J$ Cancer. 2014;110(5):1211-20.

31. Wang J, Yao L, Zhao S, Zhang X, Yin J, Zhang Y, et al. Granulocyte-colony stimulating factor promotes proliferation, migration and invasion in glioma cells. Cancer Biol Ther. 2012;13(6):389-400.

32. Demers M, Wong SL, Martinod K, Gallant M, Cabral JE, Wang Y, et al. Priming of neutrophils toward NETosis promotes tumor growth. Oncoimmunology. 2016;5(5):e1134073.

33. Brinkmann V, Reichard U, Goosmann C, Fauler B, Uhlemann Y, Weiss DS, et al. Neutrophil extracellular traps kill bacteria. Science. 2004;303(5663):1532-5.

34. Branzk N, Papayannopoulos V. Molecular mechanisms regulating NETosis in infection and disease. Semin Immunopathol. 2013;35(4):513-30.

35. Tohme S, Yazdani HO, Al-Khafaji AB, Chidi AP, Loughran P, Mowen K, et al. Neutrophil Extracellular Traps Promote the Development and Progression of Liver Metastases after Surgical Stress. Cancer Res. 2016;76(6):1367-80.

36. Xu D, Lin Y, Shen J, Zhang J, Wang J, Zhang Y, et al. Overproduced bone marrow neutrophils in collagen-induced arthritis are primed for NETosis: An ignored pathological cell involving inflammatory arthritis. Cell Prolif. 2020;53(7):e12824.

37. Arpinati L, Shaul ME, Kaisar-lluz N, Mali S, Mahroum S, Fridlender ZG. NETosis in cancer: a critical analysis of the impact of cancer on neutrophil extracellular trap (NET) release in lung cancer patients vs. mice. Cancer Immunol Immunother. 2020;69(2):199-213.

\section{Tables}

Table 1. Patient characteristics included in the study 


\begin{tabular}{|c|c|c|c|}
\hline Feature & $\begin{array}{l}\text { No rhG-CSF } \\
(n=61)\end{array}$ & $\begin{array}{l}\text { rhG-CSF } \\
(n=246)\end{array}$ & $p$ value \\
\hline Age, y & $56.52 \pm 10.22$ & $57.74 \pm 8.13$ & 0.25 \\
\hline Weight, Kg & $60.85 \pm 10.80$ & $59.40 \pm 9.51$ & 0.30 \\
\hline Gender, n (\%) & & & 0.97 \\
\hline Male & $46(75.41 \%)$ & $186(75.61 \%)$ & \\
\hline Female & $15(24.59 \%)$ & $60(24.39 \%)$ & \\
\hline Smoking, n (\%) & & & 0.96 \\
\hline Never & $24(39.34 \%)$ & $96(39.02 \%)$ & \\
\hline Former/current & $37(60.66 \%)$ & $150(60.98 \%)$ & \\
\hline Histopathology, n (\%) & & & 0.96 \\
\hline Adenocarcinoma & $29(47.54 \%)$ & $122(49.59 \%)$ & \\
\hline Squamous carcinoma & $29(47.54 \%)$ & $112(45.53 \%)$ & \\
\hline Others ${ }^{a}$ & $3(4.92 \%)$ & $12(4.88 \%)$ & \\
\hline Differentiation, n (\%) & & & 0.32 \\
\hline I & $2(3.28 \%)$ & $7(2.85 \%)$ & \\
\hline ॥ & $7(11.48 \%)$ & $52(21.14 \%)$ & \\
\hline III & $7(11.48 \%)$ & $33(13.41 \%)$ & \\
\hline NA & $45(73.77 \%)$ & $154(62.60 \%)$ & \\
\hline Clinical stage, n (\%) & & & 0.054 \\
\hline I & $17(27.87 \%)$ & $43(17.48 \%)$ & \\
\hline ॥ & $30(49.18 \%)$ & $111(45.12 \%)$ & \\
\hline III & $14(22.95 \%)$ & $92(37.40 \%)$ & \\
\hline Chemotherapy, n (\%) & & & 0.24 \\
\hline Taxane+Platinum & $28(45.90 \%)$ & $101(41.06 \%)$ & \\
\hline Gemcitabine+Platinum & $10(16.39 \%)$ & $55(22.36 \%)$ & \\
\hline Pemetrexed+Platinum & $21(34.43 \%)$ & $87(35.37 \%)$ & \\
\hline Taxane & $1(1.64 \%)$ & $1(0.41 \%)$ & \\
\hline Pemetrexed & $1(1.64 \%)$ & $0(0.00 \%)$ & \\
\hline Others ${ }^{b}$ & $0(0.00 \%)$ & $2(0.81 \%)$ & \\
\hline No. of chemotherapy, n (\%) & & & 0.01 \\
\hline$<4$ & $28(45.90 \%)$ & $72(29.27 \%)$ & \\
\hline$\geq 4$ & $33(54.10 \%)$ & $174(70.73 \%)$ & \\
\hline Myelosuppression, n (\%) & & & $<0.001$ \\
\hline 0 & $56(91.80 \%)$ & $107(43.50 \%)$ & \\
\hline 1 & $2(3.28 \%)$ & $55(22.36 \%)$ & \\
\hline 2 & $2(3.28 \%)$ & $49(19.92 \%)$ & \\
\hline
\end{tabular}

Page 10/18 


\begin{tabular}{|llll|}
\hline 3 & $0(0.00 \%)$ & $20(8.13 \%)$ & \\
\hline 4 & $1(1.64 \%)$ & $15(6.10 \%)$ & \\
\hline Fever, $n(\%)$ & & & 0.30 \\
\hline No & $58(95.08 \%)$ & $224(91.06 \%)$ & \\
\hline Yes & $3(4.92 \%)$ & $22(8.94 \%)$ & \\
\hline Antibiotic, $n(\%)$ & & & 0.64 \\
\hline No & $56(91.80 \%)$ & $221(89.84 \%)$ & \\
\hline Yes & $5(8.20 \%)$ & $25(10.16 \%)$ & \\
\hline Complications, $n(\%)$ & & & \\
\hline No & $40(65.57 \%)$ & $167(67.89 \%)$ & \\
\hline Hypertension & $9(14.75 \%)$ & $31(12.60 \%)$ & \\
\hline Tuberculosis & $2(3.28 \%)$ & $5(2.03 \%)$ & \\
\hline Gastritis/Ulcers & $3(4.92 \%)$ & $14(5.69 \%)$ & \\
\hline Hepatitis & $0(0.00 \%)$ & $9(3.66 \%)$ & \\
\hline Diabetes & $1(1.64 \%)$ & $5(2.03 \%)$ & \\
\hline Gallbladder disease & $2(3.28 \%)$ & $3(1.22 \%)$ \\
\hline Enteropatia & $1(1.64 \%)$ & $2(0.81 \%)$ \\
\hline Thyroid disease & $1(1.64 \%)$ & $3(1.22 \%)$ & \\
\hline Coronary heart disease & $1(1.64 \%)$ & $2(0.81 \%)$ & \\
\hline Chronic bronchitis/COPD & $1(1.64 \%)$ & $5(2.03 \%)$ & \\
\hline & & & \\
\hline
\end{tabular}

No.: number; NA, not available.

rhG-CSF: recombinant human granulocyte-colony stimulating factor.

COPD: chronic obstructive pulmonary disease.

aOthers: large cell neuroendocrine carcinoma, atypical carcinoid, adenosquamous carcinoma, lymphoepithelioma-like carcinoma, large cell carcinoma, pulmonary blastoma.

bOthers: Irinotecan+Platinum, Etoposide+Platinum.

Values are $n(\%)$ or mean \pm SD.

Table 2. Effects of risk factors on metastasis following operation by univariate analysis 


\begin{tabular}{|c|c|c|c|}
\hline Variables & n (\%) & $\mathrm{HR}(95 \% \mathrm{Cl})$ & $p$ value \\
\hline \multicolumn{4}{|l|}{ Histopathology } \\
\hline Others ${ }^{a}$ & $15(4.89 \%)$ & 1 & \\
\hline Adenocarcinoma & $151(49.19 \%)$ & $1.20(0.52,2.75)$ & 0.68 \\
\hline Squamous carcinoma & $141(45.93 \%)$ & $0.95(0.41,2.23)$ & 0.91 \\
\hline \multicolumn{4}{|l|}{ Differentiation } \\
\hline I & $9(2.93 \%)$ & 1 & \\
\hline ॥ & $59(19.22 \%)$ & $2.00(0.60,6.63)$ & 0.26 \\
\hline III & $40(13.03 \%)$ & $0.95(0.26,3.46)$ & 0.94 \\
\hline NA & 199 (64.82\%) & $1.74(0.55,5.51)$ & 0.34 \\
\hline \multicolumn{4}{|l|}{ Complications } \\
\hline No & $207(67.43 \%)$ & 1 & \\
\hline Yes & $100(32.57 \%)$ & $0.69(0.47,1.01)$ & 0.06 \\
\hline \multicolumn{4}{|l|}{ Clinical stage } \\
\hline I & $60(19.54 \%)$ & 1 & \\
\hline ॥ & $141(45.93 \%)$ & $1.80(1.02,3.19)$ & 0.04 \\
\hline III & $106(34.53 \%)$ & $3.61(2.04,6.36)$ & $<0.01$ \\
\hline \multicolumn{4}{|l|}{ Chemotherapy } \\
\hline Taxane+Platinum & $129(42.02 \%)$ & 1 & \\
\hline Gemcitabine+Platinum & $65(21.17 \%)$ & $1.08(0.67,1.72)$ & 0.76 \\
\hline Pemetrexed+Platinum & $108(35.18 \%)$ & $1.07(0.73,1.57)$ & 0.72 \\
\hline \multicolumn{4}{|l|}{ No. of chemotherapy } \\
\hline$<4$ & $100(32.57 \%)$ & 1 & \\
\hline$\geq 4$ & 207 (67.43\%) & $0.71(0.50,1.02)$ & 0.06 \\
\hline \multicolumn{4}{|l|}{ Myelosuppression } \\
\hline No & $163(53.09 \%)$ & 1 & \\
\hline Yes & $144(46.91 \%)$ & $0.93(0.66,1.31)$ & 0.69 \\
\hline \multicolumn{4}{|l|}{ Fever } \\
\hline No & $282(91.86 \%)$ & 1 & \\
\hline Yes & 25 (8.14\%) & $1.47(0.81,2.67)$ & 0.21 \\
\hline \multicolumn{4}{|l|}{ Antibiotic } \\
\hline No & 277 (90.23\%) & 1 & \\
\hline Yes & $30(9.77 \%)$ & $1.34(0.77,2.35)$ & 0.30 \\
\hline \multicolumn{4}{|l|}{ rhG-CSF } \\
\hline No rhG-CSF & 61 (19.87\%) & 1 & \\
\hline rhG-CSF & 246 (80.13\%) & $2.30(1.36,3.88)$ & $<0.01$ \\
\hline \multicolumn{4}{|l|}{ Dosage $(\mu \mathrm{g})$} \\
\hline 0 & $61(19.87 \%)$ & 1 & \\
\hline
\end{tabular}

Page 12/18 


\begin{tabular}{|llll|}
\hline$\leq 500$ & $96(31.27 \%)$ & $2.67(1.52,4.70)$ & $<0.01$ \\
\hline $500-1000$ & $85(27.69 \%)$ & $2.24(1.25,4.02)$ & $<0.01$ \\
\hline $1000-1500$ & $32(10.42 \%)$ & $1.63(0.80,3.35)$ & 0.18 \\
\hline$>1500$ & $33(10.75 \%)$ & $2.29(1.15,4.57)$ & 0.02 \\
\hline Dosage density $(\mu \mathrm{g} /$ day $)$ & & & \\
\hline 0 & $67(21.82 \%)$ & 1 & \\
\hline$<15$ & $71(23.13 \%)$ & $1.60(0.91,2.82)$ & 0.10 \\
\hline $15-60$ & $89(28.99 \%)$ & $1.76(1.01,3.06)$ & 0.04 \\
\hline $60-200$ & $38(12.38 \%)$ & $2.45(1.30,4.60)$ & 0.01 \\
\hline$\geq 200$ & $42(13.68 \%)$ & $3.89(2.12,7.12)$ & $<0.01$ \\
\hline
\end{tabular}

HR: hazard ratio; Cl: confidence interval; rhG-CSF: recombinant human granulocyte-colony stimulating factor; No.: number; NA: not available.

aOthers: large cell neuroendocrine carcinoma, atypical carcinoid, adenosquamous carcinoma, lymphoepithelioma-like carcinoma, large cell carcinoma, pulmonary blastoma.

Table3. Effect of any rhG-CSF use on metastasis following operation in NSCLC 


\begin{tabular}{|c|c|c|c|c|c|c|c|c|}
\hline & Total, & Events, $\mathrm{n}$ & Non-adjusted & & Adjusted I & & Adjusted II & \\
\hline & & & $\mathrm{HR}(95 \% \mathrm{Cl})$ & $p$ & $\mathrm{HR}(95 \% \mathrm{Cl})$ & $p$ & $\mathrm{HR}(95 \% \mathrm{Cl})$ & $p$ \\
\hline \multicolumn{9}{|l|}{ rhG-CSF } \\
\hline No rhG-CSF & 61 & $16(26.23 \%)$ & 1 & & 1 & & 1 & \\
\hline rhG-CSF & 246 & $\begin{array}{l}119 \\
(48.37 \%)\end{array}$ & $\begin{array}{l}2.30(1.36, \\
3.88)\end{array}$ & $<0.01$ & $\begin{array}{l}2.41(1.42, \\
4.11)\end{array}$ & $<0.01$ & $\begin{array}{l}2.33(1.31 \\
4.15)\end{array}$ & $<0.01$ \\
\hline \multicolumn{9}{|l|}{ Dosage $(\mu \mathrm{g})$} \\
\hline 0 & 61 & $16(26.23 \%)$ & 1 & & 1 & & 1 & \\
\hline$\leq 500$ & 96 & 49 (51.04\%) & $\begin{array}{l}2.67(1.52, \\
4.70)\end{array}$ & $<0.01$ & $\begin{array}{l}2.86(1.61, \\
5.08)\end{array}$ & $<0.01$ & $\begin{array}{l}2.74(1.50 \\
5.02)\end{array}$ & $<0.01$ \\
\hline $500-1000$ & 85 & $38(44.71 \%)$ & $\begin{array}{l}2.24(1.25, \\
4.02)\end{array}$ & $<0.01$ & $\begin{array}{l}2.32(1.28, \\
4.18)\end{array}$ & $<0.01$ & $\begin{array}{l}2.30(1.20 \\
4.43)\end{array}$ & 0.01 \\
\hline $1000-1500$ & 32 & $14(43.75 \%)$ & $\begin{array}{l}1.63(0.80 \\
3.35)\end{array}$ & 0.18 & $\begin{array}{l}1.68(0.81 \\
3.50)\end{array}$ & 0.16 & $\begin{array}{l}1.48(0.69 \\
3.18)\end{array}$ & 0.32 \\
\hline$>1500$ & 33 & $18(54.55 \%)$ & $\begin{array}{l}2.29(1.15, \\
4.57)\end{array}$ & 0.02 & $\begin{array}{l}2.41(1.20 \\
4.84)\end{array}$ & 0.01 & $\begin{array}{l}2.16(0.98 \\
4.47)\end{array}$ & 0.06 \\
\hline$p$ for trend & - & - & & 0.33 & & 0.33 & & 0.93 \\
\hline \multicolumn{9}{|c|}{$\begin{array}{l}\text { Dosage density } \\
\text { ( } \mathrm{g} / \text { day })\end{array}$} \\
\hline 0 & 67 & $19(28.36 \%)$ & 1 & & 1 & & 1 & \\
\hline$<15$ & 71 & $34(47.89 \%)$ & $\begin{array}{l}1.60(0.91 \\
2.82)\end{array}$ & 0.10 & $\begin{array}{l}1.65(0.93 \\
2.92)\end{array}$ & 0.05 & $\begin{array}{l}1.54(0.82 \\
2.90)\end{array}$ & 0.18 \\
\hline $15-60$ & 89 & $38(42.70 \%)$ & $\begin{array}{l}1.76(1.01 \\
3.06)\end{array}$ & 0.04 & $\begin{array}{l}1.80(1.03 \\
3.14)\end{array}$ & 0.04 & $\begin{array}{l}1.50(0.81 \\
2.81)\end{array}$ & 0.20 \\
\hline $60-200$ & 38 & $20(52.63 \%)$ & $\begin{array}{l}2.45(1.30 \\
4.60)\end{array}$ & $<0.01$ & $\begin{array}{l}2.73(1.44 \\
5.18)\end{array}$ & 0.01 & $\begin{array}{l}2.07 \text { (1.04, } \\
4.09)\end{array}$ & 0.04 \\
\hline$\geq 200$ & 42 & $24(57.14 \%)$ & $\begin{array}{l}3.89(2.12, \\
7.12)\end{array}$ & $<0.01$ & $\begin{array}{l}3.80(2.06, \\
7.01)\end{array}$ & $<0.01$ & $\begin{array}{l}3.36(1.77 \\
6.37)\end{array}$ & $<0.001$ \\
\hline$p$ for trend & & & & $<0.001$ & & $<0.001$ & & $<0.001$ \\
\hline
\end{tabular}

HR: hazard ratio; Cl: confidence interval; rhG-CSF: recombinant human granulocyte-colony stimulating factor.

Non-adjusted model adjust for: None.

Adjusted I model adjust for: Age, Sex, Weight, Smoking.

Adjusted II model adjust for: Age, Sex, Weight, Smoking, Histopathology, Differentiation, Complications, Clinical stage, Chemotherapy, Number of chemotherapy, Myelosuppression, Fever, Antibiotic.

Table4. Effect of any ihG-CSF use on metastasis following postoperative chemotherapy in NSCLC by follow-up 1year, 2 year and 3 year. 


\begin{tabular}{|c|c|c|c|c|c|c|c|c|c|c|}
\hline & \multicolumn{4}{|c|}{ Follow-up 1 Year } & \multicolumn{3}{|c|}{ Follow-up 2 Year } & \multicolumn{3}{|c|}{ Follow-up 3 Year } \\
\hline & $\begin{array}{l}\text { Total, } \\
\mathbf{n}\end{array}$ & $\begin{array}{l}\text { Events, } \mathrm{n} \\
(\%)\end{array}$ & Adjusted I & Adjusted II & $\begin{array}{l}\text { Events, } \mathrm{n} \\
\text { (\%) }\end{array}$ & $\begin{array}{l}\text { Adjusted } \\
\text { I }\end{array}$ & $\begin{array}{l}\text { Adjust } \\
\text { II }\end{array}$ & $\begin{array}{l}\text { Events, } \mathrm{n} \\
\text { (\%) }\end{array}$ & Adjusted & $\begin{array}{l}\text { Adjusted } \\
\text { II }\end{array}$ \\
\hline & & & $\mathrm{HR}(95 \% \mathrm{Cl})$ & $\mathrm{HR}(95 \% \mathrm{Cl})$ & & $\begin{array}{l}\mathrm{HR}(95 \% \\
\mathrm{Cl})\end{array}$ & $\begin{array}{l}\text { HR } \\
(95 \% \\
\text { Cl) }\end{array}$ & & $\begin{array}{l}\mathrm{HR}(95 \% \\
\mathrm{Cl})\end{array}$ & $\begin{array}{l}\mathrm{HR}(95 \% \\
\mathrm{Cl})\end{array}$ \\
\hline \multicolumn{11}{|l|}{ hG-CSF } \\
\hline $\begin{array}{l}\text { No rhG- } \\
\text { CSF }\end{array}$ & 61 & $\begin{array}{l}4 \\
(6.56 \%)\end{array}$ & 1 & 1 & $\begin{array}{l}8 \\
(13.11 \%)\end{array}$ & 1 & 1 & $\begin{array}{l}12 \\
(19.67 \%)\end{array}$ & 1 & 1 \\
\hline rhG-CSF & 246 & $\begin{array}{l}54 \\
(21.95 \%)\end{array}$ & $\begin{array}{l}4.02 \\
(1.45,11.11)\end{array}$ & $\begin{array}{l}4.44 \\
(1.54,12.79)\end{array}$ & $\begin{array}{l}80 \\
(32.52 \%)\end{array}$ & $\begin{array}{l}3.17 \\
(1.53 \\
6.58)\end{array}$ & $\begin{array}{l}2.91 \\
(1.34 \\
6.29)\end{array}$ & $\begin{array}{l}101 \\
(41.05 \%)\end{array}$ & $\begin{array}{l}2.66 \\
(1.45 \\
4.86)\end{array}$ & $\begin{array}{l}2.53 \\
(1.32 \\
4.82)\end{array}$ \\
\hline \multicolumn{11}{|l|}{$\begin{array}{l}\text { Doseage } \\
(\mu \mathrm{g})\end{array}$} \\
\hline 0 & 61 & $\begin{array}{l}4 \\
(6.56 \%)\end{array}$ & 1 & 1 & $\begin{array}{l}8 \\
(13.11 \%)\end{array}$ & 1 & 1 & $\begin{array}{l}12 \\
(19.67 \%)\end{array}$ & 1 & 1 \\
\hline$\leq 500$ & 96 & $\begin{array}{l}19 \\
(19.79 \%)\end{array}$ & $\begin{array}{l}3.74(1.27 \\
11.01)\end{array}$ & $\begin{array}{l}4.09(1.36 \\
12.34)\end{array}$ & $\begin{array}{l}32 \\
(33.33 \%)\end{array}$ & $\begin{array}{l}3.37 \\
(1.55 \\
7.33)\end{array}$ & $\begin{array}{l}3.13 \\
(1.40 \\
7.00)\end{array}$ & $\begin{array}{l}41 \\
(42.71 \%)\end{array}$ & $\begin{array}{l}2.91 \\
(1.52 \\
5.57)\end{array}$ & $\begin{array}{l}2.76 \\
(1.41 \\
5.43)\end{array}$ \\
\hline $\begin{array}{l}500- \\
1000\end{array}$ & 85 & $\begin{array}{l}20 \\
(23.53 \%)\end{array}$ & $\begin{array}{l}4.36(1.49 \\
12.82)\end{array}$ & $\begin{array}{l}5.36(1.70 \\
16.89)\end{array}$ & $\begin{array}{l}26 \\
(30.59 \%)\end{array}$ & $\begin{array}{l}3.00 \\
(1.35 \\
6.65)\end{array}$ & $\begin{array}{l}2.79 \\
(1.18 \\
6.64)\end{array}$ & $\begin{array}{l}32 \\
(37.65 \%)\end{array}$ & $\begin{array}{l}2.47 \\
(1.29 \\
4.82)\end{array}$ & $\begin{array}{l}2.50 \\
(1.20 \\
5.20)\end{array}$ \\
\hline $\begin{array}{l}1000- \\
1500\end{array}$ & 32 & $\begin{array}{l}6 \\
(18.75 \%)\end{array}$ & $\begin{array}{l}2.97(0.84 \\
10.58)\end{array}$ & $\begin{array}{l}3.57(0.96 \\
13.27)\end{array}$ & $\begin{array}{l}10 \\
(31.25 \%)\end{array}$ & $\begin{array}{l}2.53 \\
(0.99 \\
6.47)\end{array}$ & $\begin{array}{l}2.30 \\
(0.87 \\
6.06)\end{array}$ & $\begin{array}{l}13 \\
(40.63 \%)\end{array}$ & $\begin{array}{l}2.06 \\
(0.93 \\
4.57)\end{array}$ & $\begin{array}{l}1.88 \\
(0.82 \\
4.31)\end{array}$ \\
\hline$>1500$ & 33 & $\begin{array}{l}9 \\
(27.27 \%)\end{array}$ & $\begin{array}{l}5.21(1.59 \\
17.01)\end{array}$ & $\begin{array}{l}7.18(1.96 \\
26.26)\end{array}$ & $\begin{array}{l}12 \\
(36.36 \%)\end{array}$ & $\begin{array}{l}3.88 \\
(1.58 \\
9.54)\end{array}$ & $\begin{array}{l}3.88 \\
(1.42 \\
10.59)\end{array}$ & $\begin{array}{l}15 \\
(45.45 \%)\end{array}$ & $\begin{array}{l}3.18 \\
(1.48 \\
6.82)\end{array}$ & $\begin{array}{l}3.12 \\
(1.32 \\
7.38)\end{array}$ \\
\hline $\begin{array}{l}p \text { for } \\
\text { trend }\end{array}$ & & & 0.04 & 0.03 & & 0.05 & 0.16 & & 0.08 & 0.23 \\
\hline \multicolumn{11}{|l|}{$\begin{array}{l}\text { Dose } \\
\text { density } \\
\text { ( } \mu \mathrm{g} / \text { day) }\end{array}$} \\
\hline 0 & 67 & $\begin{array}{l}5 \\
(7.46 \%)\end{array}$ & 1 & 1 & $\begin{array}{l}10 \\
(14.93 \%)\end{array}$ & 1 & 1 & $\begin{array}{l}15 \\
(22.39 \%)\end{array}$ & 1 & 1 \\
\hline$<15$ & 71 & $\begin{array}{l}13 \\
(18.31 \%)\end{array}$ & $\begin{array}{l}2.52(0.90 \\
7.08)\end{array}$ & $\begin{array}{l}2.91 \\
8.75)\end{array}$ & $\begin{array}{l}20 \\
(28.17 \%)\end{array}$ & $\begin{array}{l}1.97 \\
(0.92 \\
4.23)\end{array}$ & $\begin{array}{l}1.89 \\
(0.83 \\
4.3)\end{array}$ & $\begin{array}{l}29 \\
(40.85 \%)\end{array}$ & $\begin{array}{l}1.83 \\
(0.98 \\
3.42)\end{array}$ & $\begin{array}{l}1.79 \\
(0.90 \\
3.55)\end{array}$ \\
\hline $15-60$ & 89 & $\begin{array}{l}21 \\
(13.16 \%)\end{array}$ & $\begin{array}{l}3.65(1.37 \\
9.71)\end{array}$ & $\begin{array}{l}3.74(1.31 \\
10.67)\end{array}$ & $\begin{array}{l}28 \\
(31.46 \%)\end{array}$ & $\begin{array}{l}2.63 \\
(1.27 \\
5.42)\end{array}$ & $\begin{array}{l}2.16 \\
(0.98 \\
4.76)\end{array}$ & $\begin{array}{l}31 \\
(34.83 \%)\end{array}$ & $\begin{array}{l}1.87 \\
(1.01 \\
3.48)\end{array}$ & $\begin{array}{l}1.59 \\
(0.80 \\
3.15)\end{array}$ \\
\hline $60-200$ & 38 & $\begin{array}{l}5 \\
(13.16 \%)\end{array}$ & $\begin{array}{l}2.25(0.65 \\
7.84)\end{array}$ & $\begin{array}{l}1.97(0.55 \\
7.15)\end{array}$ & $\begin{array}{l}11 \\
(28.95 \%)\end{array}$ & $\begin{array}{l}2.48 \\
(1.05 \\
5.88)\end{array}$ & $\begin{array}{l}1.83 \\
(0.74 \\
4.51)\end{array}$ & $\begin{array}{l}16 \\
(42.11 \%)\end{array}$ & $\begin{array}{l}2.51 \\
(1.23 \\
5.12)\end{array}$ & $\begin{array}{l}1.88 \\
(0.89 \\
3.97)\end{array}$ \\
\hline$\geq 200$ & 42 & $\begin{array}{l}14 \\
(33.33 \%)\end{array}$ & $\begin{array}{l}6.13(2.19 \\
17.11)\end{array}$ & $\begin{array}{l}5.88(2.06 \\
16.85)\end{array}$ & $\begin{array}{l}19 \\
(45.24 \%)\end{array}$ & $\begin{array}{l}4.97 \\
(2.3, \\
10.75)\end{array}$ & $\begin{array}{l}4.18 \\
(1.88 \\
9.29)\end{array}$ & $\begin{array}{l}22 \\
(52.38 \%)\end{array}$ & $\begin{array}{l}4.09 \\
(2.11 \\
7.94)\end{array}$ & $\begin{array}{l}3.38 \\
(1.69 \\
6.74)\end{array}$ \\
\hline $\begin{array}{l}p \text { for } \\
\text { trend }\end{array}$ & & & $<0.001$ & 0.01 & & $<0.001$ & $<0.001$ & & $<0.001$ & $<0.001$ \\
\hline
\end{tabular}

HR: hazard ratio; Cl: confidence interval; rhG-CSF: recombinant human granulocyte-colony stimulating factor;

Adjusted I model adjust for: Age; Sex; Weight; Smoking 
Adjusted II model adjust for: Age; Sex; Weight; Smoking; Histopathology; Differentiation; Complications; Clinical stage; Chemotherapy; Number of chemotherapy; Myelosuppression; Fever; Antibiotic

Figures

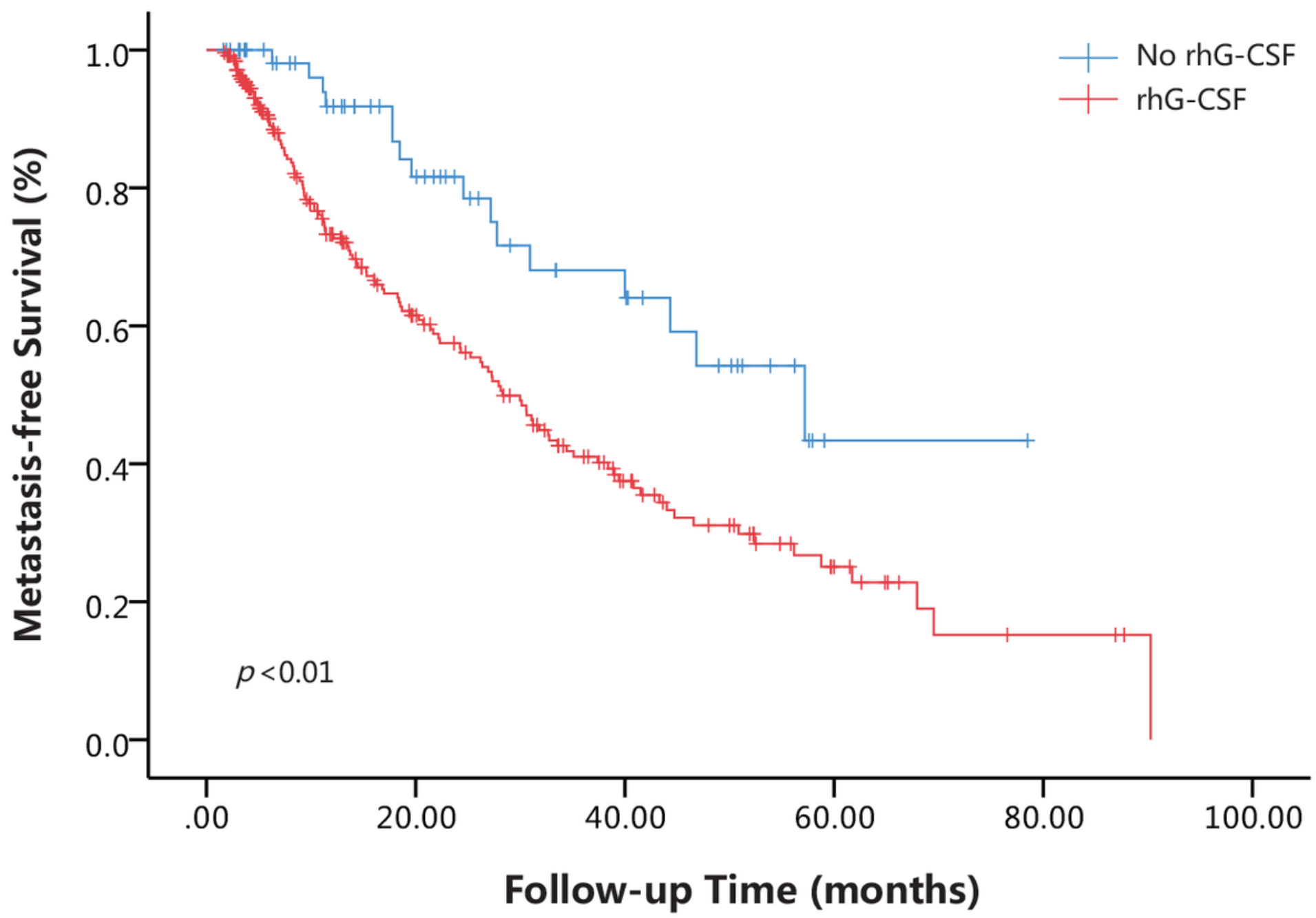

Figure 1

Kaplan-Meier curves of metastasis-free survival (MFS) for postoperative NSCLC patients accepted chemotherapy stratified by No rhGCSF and rhG-CSF.

A

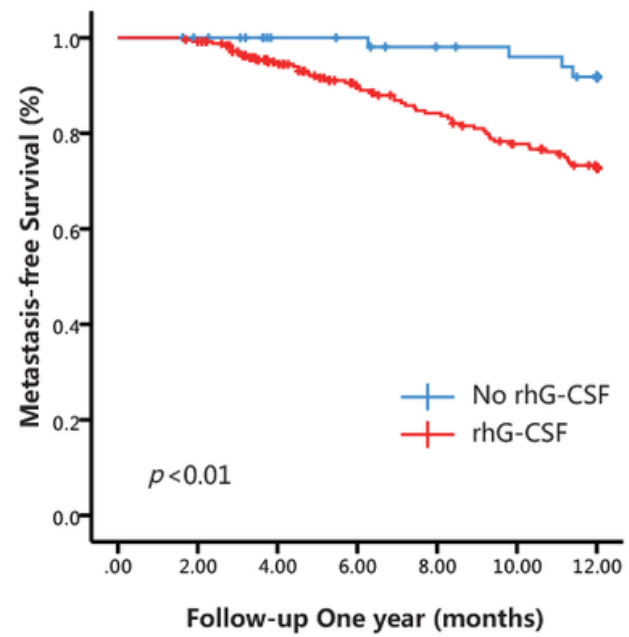

B

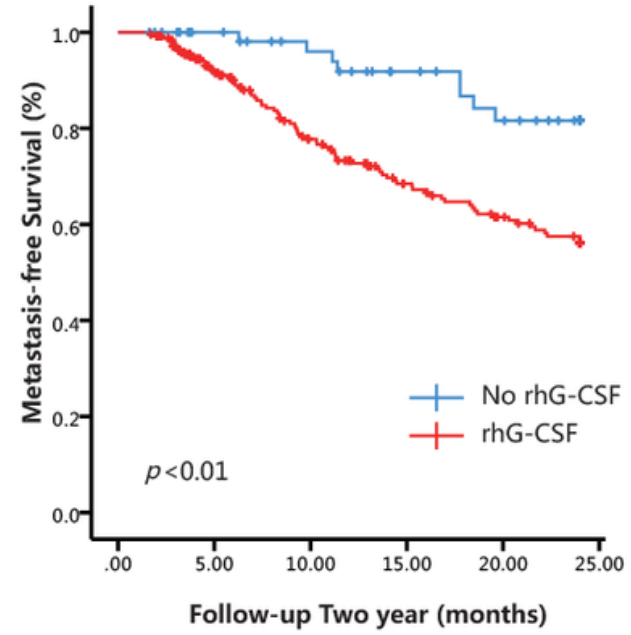

C

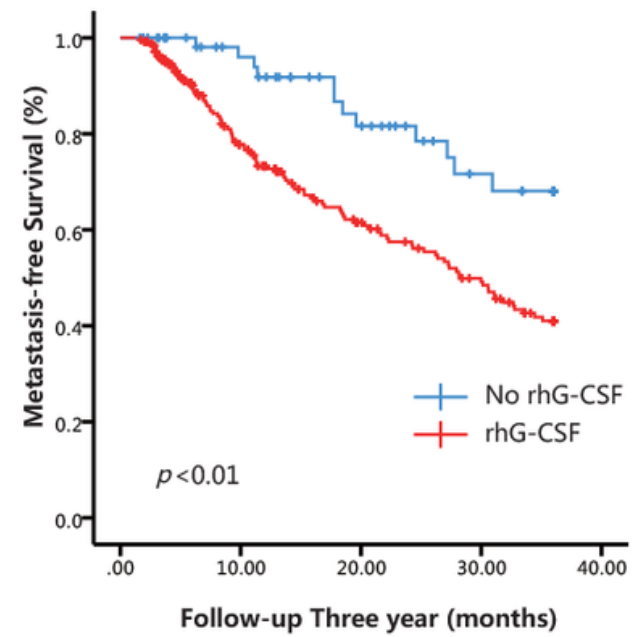

Page 16/18 
Figure 2

Kaplan-Meier curves of metastasis-free survival (MFS) for postoperative NSCLC patients accepted chemotherapy during different followup times stratified by No rhG-CSF and rhG-CSF. A-C: follow-up postoperative NSCLC patients accepted chemotherapy one, two, and three years.

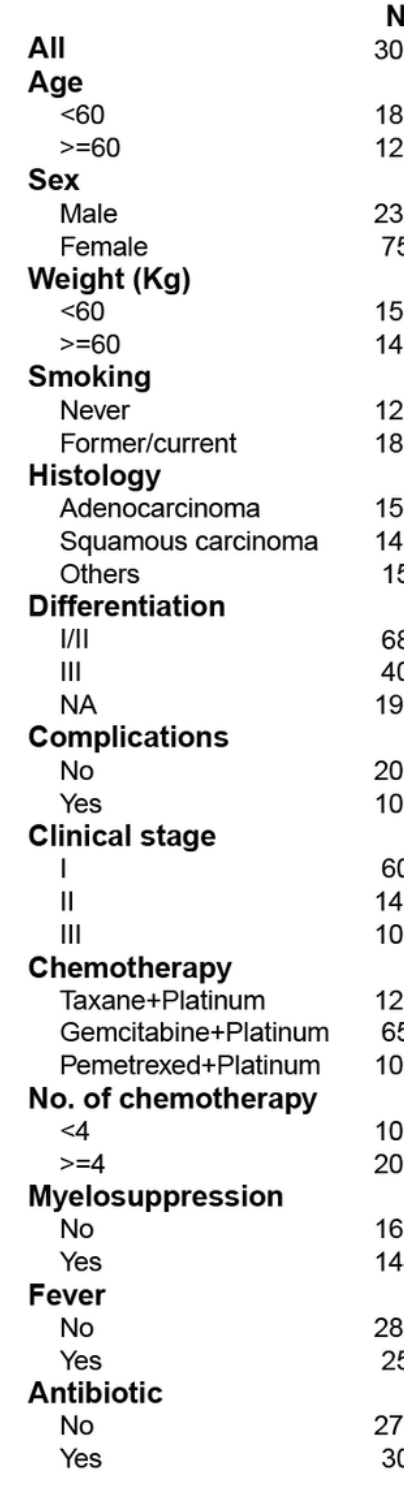

\section{N}

307

181

126

232

75

159

148

120

187

151

141

15

68

40
199

207

100

60

141

106

129

129
65
108

108

100

207

163

144

282

25

277

30

\section{$\begin{array}{ccc}\text { HR } & \mathbf{9 5} \% \mathbf{C l} & \text { Interaction } \boldsymbol{p} \text {-value } \\ 2.30 & (1.36,3.88)\end{array}$}

$\begin{array}{lll}2.76 & (1.42,5.37) & 0.40\end{array}$

$1.72 \quad(0.73,4.04)$

$2.57 \quad(1.41,4.70) \quad 0.57$

$1.78 \quad(0.62,5.11)$

$\begin{array}{lll}1.76 & (0.83,3.70) & 0.30\end{array}$

$3.15 \quad(1.50,6.62)$

$2.93 \quad(1.26,6.81) \quad 0.37$

$1.91 \quad(0.98,3.73)$

$2.29 \quad(1.14,4.59) \quad 0.93$

$2.17 \quad(0.92,5.12)$

$3.51 \quad(0.40,30.47)$

$\begin{array}{lll}3.92 & (0.92,16.66) & 0.12\end{array}$

$0.22 \quad(0.04,1.40)$

$2.50 \quad(1.36,4.59)$

$2.25 \quad(1.25,4.04) \quad 0.73$

$2.79 \quad(0.85,9.12)$

$\begin{array}{lll}2.17 & (0.60,7.82) & 0.25\end{array}$

$2.7 \quad(1.16,6.31)$

$1.09 \quad(0.49,2.41)$

$\begin{array}{lll}3.15 & (1.34,7.43) & 4.48\end{array}$

$2.40 \quad(0.57,10.19)$

$1.49 \quad(0.70,3.15)$

$\begin{array}{lll}1.90 & (0.91,3.96) & 0.38\end{array}$

$3.12 \quad(1.44,6.75)$

$3.34 \quad(1.86,6.02) \quad<0.01$

$0.71 \quad(0.17,2.94)$

$2.24 \quad(1.30,3.84) \quad 0.72$

$2.61 \quad(0.33,20.46)$

$2.27 \quad(1.30,3.97)$

$2.15 \quad(0.48,9.71)$

0.80

0.80

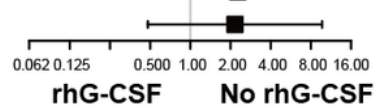

\section{Figure 3}

Subgroup analysis on effect of rhG-CSF on tumor metastasis in postoperative NSCLC patients accepted chemotherapy. 


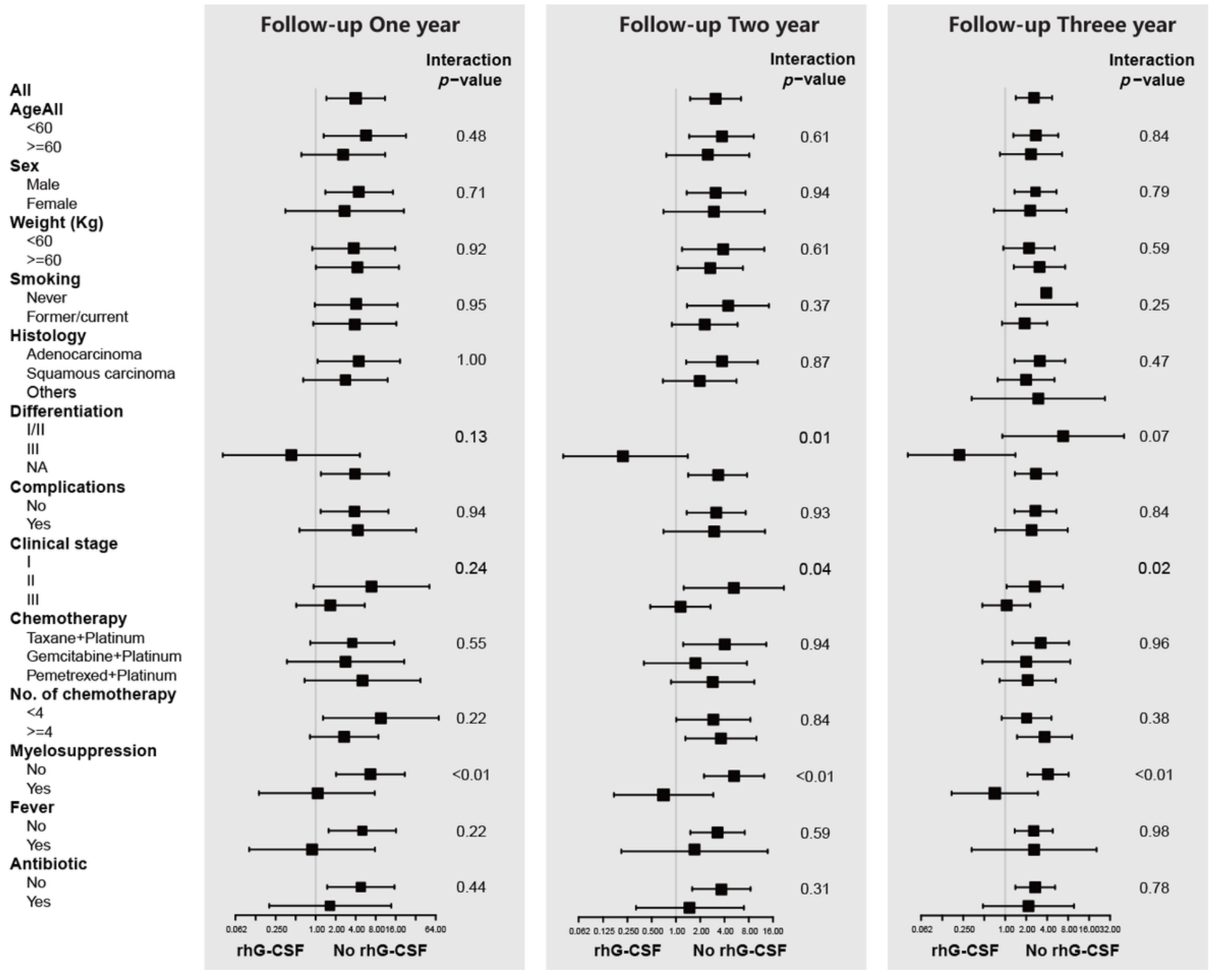

Figure 4

Subgroup analyses on effect of rhG-CSF on tumor metastasis in postoperative NSCLC patients accepted chemotherapy during different follow-up times. A-C: follow-up postoperative NSCLC patients accepted chemotherapy one, two, and three years. 